\title{
Macrobenthic Community in Tolo Harbour, Hong Kong and its Relations with Heavy Metals
}

\author{
Kouping Chen • Shengyan Tian • Jiu Jimmy Jiao
}

Received: 18 June 2009/Revised: 27 November 2009 /Accepted: 25 January 2010 /Published online: 26 February 2010

(C) Coastal and Estuarine Research Federation 2010

\begin{abstract}
The present study investigated the macrobenthic community in Tolo Harbour, Hong Kong, aiming at linking heavy metal concentrations to differences in macrobenthic community. The stations investigated in Tolo Harbour have widely contrasting features, with some areas located in the Plove Cove displaying both high species richness and abundance while other areas displaying quite impoverished or even void of macrobenthos. High diversity and abundance of macrobenthos in areas with low heavy metal concentrations were recorded. Strong negative correlation between macrobenthic diversity and heavy metal concentrations was found, and this implicated the pollutioninduced degradation of macrobenthos in some locations in Tolo Harbour. These results support the Pearson-Rosenberg model for succession along a pollution gradient.
\end{abstract}

Keywords Macrobenthos · Heavy metal · Tolo Harbour · Hong Kong

\section{Introduction}

Harbors are among the most altered coastal areas. They are usually enclosed areas characterized by low mixing and

\section{K. Chen}

Center for Hydrosciences Research, Nanjing University,

Nanjing, China

K. Chen $(\bowtie) \cdot$ J. J. Jiao

Department of Earth Sciences, The University of Hong Kong, Hong Kong, China

e-mail:kpchen@graduate.hku.hk

S. Tian

College of Marine Science and Engineering,

Tianjin University of Science and Technology,

Tianjin, China exchange with open waters, reduced oxygen in the water column, and high sediment pollution levels (Guerra-García and García-Góme 2004). Harbors can be seen as unique ecosystems structured by abiotic factors which may determine faunal distribution and abundance (Chapman and Wang 2001). This often makes the interpretation of the disturbing effects of contaminants a complex and confounding process. In the literature, there have been fewer studies of the macrofauna of harbors than of other shallow water environment. However, it is well known that macrobenthic fauna within harbors is generally suffering and impoverished (Estacio et al. 1997). Mucha et al. (2003) stated that sediment pollution posed one of the worst environmental problems to coastal ecosystems. The relationship between macrobenthic community structure and heavy metal contamination has been studied by previous researchers (Rygg 1985a; Hall et al. 1996; Warwick 2001; Guerra-García and García-Góme 2004; Harriague et al. 2007; Dauvin 2008). Rygg (1985a) studied the relationship between species diversity in benthic fauna communities and concentrations of heavy metals $(\mathrm{Cu}, \mathrm{Pb}$, and $\mathrm{Zn})$ and organic matter in the sediments from Norwegian fjords. He found a strong negative correlation between species diversity and $\mathrm{Cu}$ concentration, and high concentration of $\mathrm{Cu}$ in sediments proved toxic to a number of species such as Glycera rouxii, Phylo norvegica, Sosane gracilis, Terebellides stroemi, Eriopisa elongate, and Ennucula tenuis, thus lowering diversity. Hall et al. (1996) studied the effects of metal contamination on macrobenthos in two North Sea estuaries and found that macrobenthic communities in both estuaries appeared to respond positively to large reductions in the inputs of contaminants. Warwick (2001) investigated the effects of metal contamination on the intertidal macrobenthic assemblages of the Fal Estuary and concluded that of all environmental factors, heavy metal concentrations in the sediments correlated most 
strongly with the composition of the biological communities. Guerra-García and García-Góme (2004) investigated polychaete assemblages and sediment pollution in Ceuta Harbour with two opposing entrances. They suggested that pollution gradient was the main factor affecting polychaete distribution, and also polychaete species richness and diversity in sediments inside Ceuta Harbour were higher than in conventional harbors due to the positive effects of increased water renewal. Dauvin (2008) found that the response to metal contaminants varied among species, and heavy metals explained only part of the variation in benthic community structure. According to Chen and Jiao (2010), Tolo Harbour is anthropogenically contaminated with high levels of heavy metals in the sediments, but so far, the effect of contaminated sediments on the diversity and structure of the macrobenthic community has not been investigated. The purposes of this paper were to present the status of the macrobenthic community in Tolo Harbour, Hong Kong and to investigate the relation between the levels of heavy metals in sediments and macrobenthic community.

\section{Materials and Methods}

\section{Study Area}

Tolo Harbour, an almost land-locked estuary located in the northeastern territories of Hong Kong (Fig. 1), is enclosed by a large catchment area of around $50 \mathrm{~km}^{2}$. The catchment is formed by three main mountainous blocks divided by the new towns Tai Po and Sha Tin (Fig. 1). These mountains include Wong Leng $(639 \mathrm{~m})$ and Pat Sin Leng (500$600 \mathrm{~m}$ ), which are close to Plover Cove; Tai Mo Shan (957 m), Grassy Hill (647 m), Ma On Shan (702 m), and Buffalo Hill $(604 \mathrm{~m})$, which form the western and eastern flanks of Sha Tin. Tolo Harbour receives natural and anthropogenic inputs from upstream, metropolitan areas and industries located on or near these areas. Yim (1984) documented that natural inputs of $\mathrm{Pb}$ and $\mathrm{Zn}$ were derived from the breakdown of sulfide minerals such as galena and sphalerite in the mineralized volcanic rocks in the Tai Mo Shan area (Fig. 1). These sulfide minerals were also present in the alluvial boulders and cobbles of the Lam Tsuen Valley which is located upstream of Tai Po. The state of heavy metal pollution in the harbor has attracted much public attention since the early 1970s. A few decades ago, the harbor was enclosed by rural areas. Since the middle of the 1950s, rapid growth of the manufacturing industries, population expansion, and rapid urban development around this area have resulted in substantial pollution problems which seriously affected the environment in Tolo Harbour.

The main water body of the harbor is approximately $16 \mathrm{~km}$ long and $3 \mathrm{~km}$ wide and connected to the Mirs Bay through Tolo Channel, a very narrow channel with a maximum width of only $1.3 \mathrm{~km}$. Xu et al. (2004) estimated that the currents in inner harbor and Tolo Channel were $0.04-0.08$ and $0.08 \mathrm{~m} / \mathrm{s}$, respectively. Plover Cove, which is located north of the study area (Fig. 1), is relatively isolated from the inner harbor. The pollutants accumulate in the bottom sediments because of the low currents, bottlenecked coastline of the study area, and increased urban and industrial activities.

The study area is dominated by volcanic rocks which contain a complex granite pluton. A mantle of weathered rock occurs over most of the district which can be several meters thick. The superficial soils, including the mantle of weathered rock, colluvium, alluvium, and beach sand are considered to form a shallow unconfined aquifer (Tse and Jiao 2008). There may be fracture zones along the rockhead below the decomposed rock which form a relatively deep aquifer (Jiao et al. 2005, 2006).

\section{Field Sampling}

Seabed sediment collection for this study was carried out on board the Electronic \& Geophysical Services (Asia) Limited's Class Survey vessel from 18 to 20 November in 2006. A differential global positioning system was used to locate the sampling sites. The locations of sampling sites were shown in Fig. 1. In total, 13 sampling sites in Tolo Harbour were collected for this study.

All sediment samples were taken with a $0.05-\mathrm{m}^{2}$ van Veen grab. At every sampling site, six replicate grab samples were collected. One grab sample was used for the analysis of heavy metal concentrations and was stored in a plastic bag. Five additional replicate samples were used for the analysis of macrobenthos, the samples were sieved on a $0.5-\mathrm{mm}$ sieve, and residues retained on the sieve were transferred into plastic container and fixed with 5\% boraxbuffered formalin followed by staining with $1 \%$ Rose Bengal for later sorting and identification. All sediment samples were stored in an ice box on board.

\section{Laboratory Analysis}

Sediment residues for macrobenthos analysis were sorted under a dissecting microscope and animals were identified to the lowest possible taxon (usually to species level) and enumerated. Data on individuals per species were used to calculate the various biological parameters such as abundance, number of species, species richness, evenness, and Shannon diversity index (Shannon and Weaver 1963). In soft sediment macrobenthos studies, a single grab, covering only $0.05 \mathrm{~m}^{2}$, is known to sample only a small fraction of species at each site; therefore, data analyses were done on species abundance data pooled over five replicate grabs from each site 


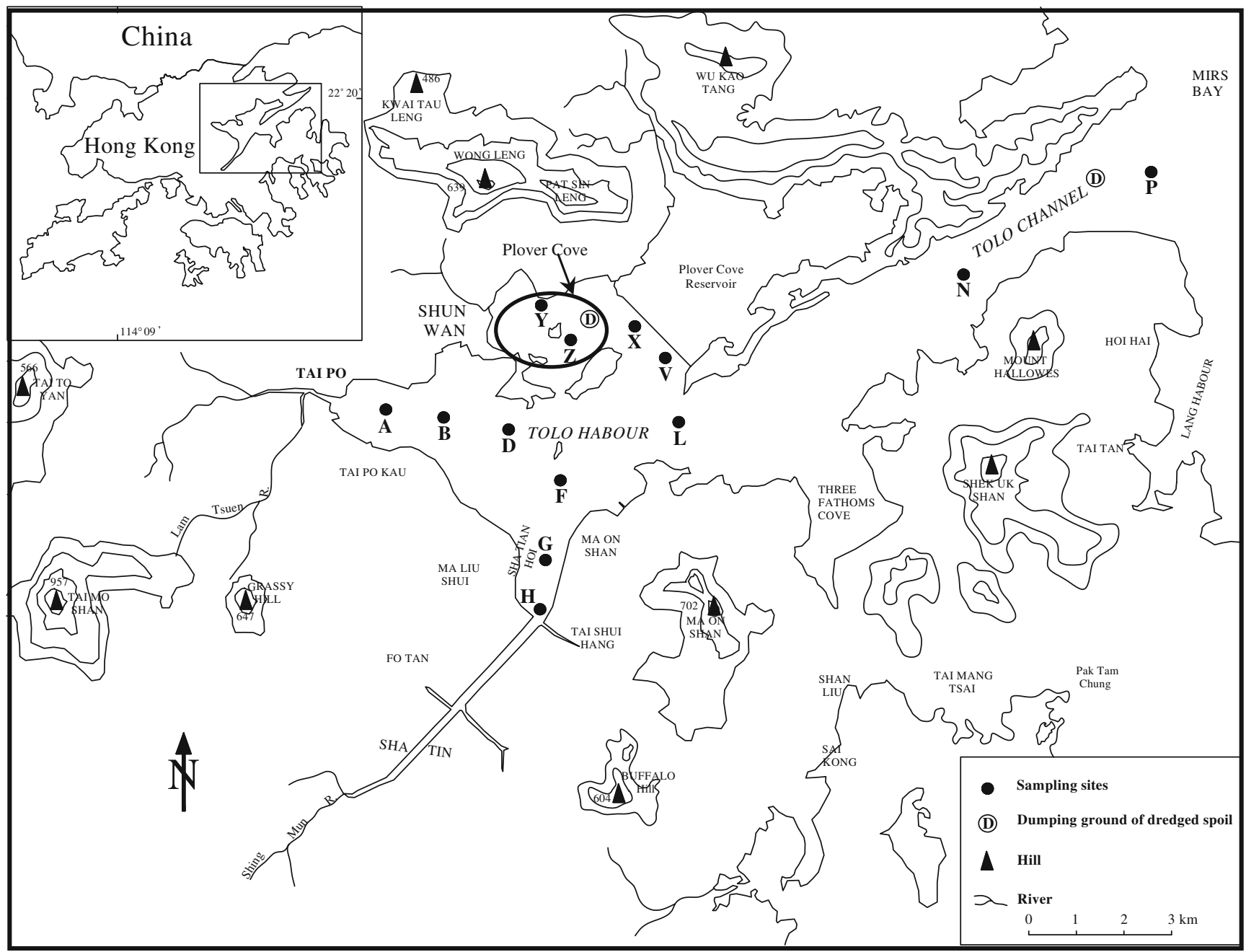

Fig. 1 Map of the study area with sampling stations for macrofauna and heavy metals

$\left(0.25 \mathrm{~m}^{2}\right)$, which was designated a "sample" (Gray 1994; Ellingsen and Gray 2002; Shin and Ellingsen 2004).

Sediment heavy metal analysis was carried out at The University of Hong Kong. The collected marine sediment samples were oven-dried at $80^{\circ} \mathrm{C}$ for 2 days, then ground using an agate mortar and pestle to obtain homogenous powder. The prepared samples were analyzed for metal concentrations using an acid digestion $\left(\mathrm{HNO}_{3}\right.$ and $\left.\mathrm{HF}\right)$ method. In this method, each sample $(0.05 \mathrm{~g})$ was digested using a 2-mL mixture of ultrapure $\mathrm{HNO}_{3} / \mathrm{HF}$ (1:1) in a sealed polytetrafluoroethylene bomb heated at $190^{\circ} \mathrm{C}$ in an electric oven for $24 \mathrm{~h}$. After cooling, the bombs were opened and placed on a hot plate (at around $150^{\circ} \mathrm{C}$ ) until the solutions were evaporated to dryness. The final residue was redissolved by adding $2 \mathrm{~mL}$ ultrapure $\mathrm{HNO}_{3}$ and $4 \mathrm{~mL}$ deionized water. At the same time, $1 \mathrm{~mL}$ of $500 \mathrm{ng} / \mathrm{mL} \mathrm{Rh}$ solution was added as an internal standard. The resealed bombs were returned to the electric oven and heated to $140^{\circ} \mathrm{C}$ for $4 \mathrm{~h}$. After cooling, the final volume was made up to $50 \mathrm{~mL}$ by the addition of deionized water, and the samples were stored in a PVC bottle at $4{ }^{\circ} \mathrm{C}$ prior to analysis by inductively coupled plasma-mass spectrometer (model VG EXCELL). The reagent blanks were treated in the same way as the marine sediment samples.

\section{Results and Discussions}

\section{Characteristics of Macrobenthic Fauna}

In this study, a total of 77 species were recorded from the 13 sampling sites in Tolo Harbour. Many species such as Cossuridae, Spionidae, Phyllodocidae, and Capitellidae belonging to the polychaetes have been identified as opportunistic species by several authors (Grassle and Grassle 1974; Pearson and Rosenberg 1978). Polychaetes (48 species) constituted $62.33 \%$ of the total number of species; mollusks (18 species), crustaceans (seven species), and echinoderms (four species) comprised 23.38\%, 9.09\%, and $5.19 \%$, respectively. Fish species were found at site P 
only, representing two distinct species with eight individuals in total. Of the ten most abundant species, six were polychaetes, two were mollusks, one was a crustacean, and one was an echinoderm (Table 1). The most dominant species was polychaete Pherusa sp. which accounted for $38.38 \%$ of total macrofauna abundance, and it was mainly found at site $\mathrm{Y}(8,540$ individuals at site $\mathrm{Y})$. No species spanned the whole sampling areas. The most widespread species was polychaete Pilargis verrucosa pacifica present at six sites, while 50 species were rare and occurred only at one site. In a study of soft sediment macrobenthos along the Norwegian continental shelf, Ellingsen and Gray (2002) took samples with a $0.1-\mathrm{m}^{2}$ van Veen grab and washed biological samples through a 1-mm round hole diameter sieve; they recorded 477 species from an area (25 sites, $\left.12.5 \mathrm{~m}^{2}\right)$ in the southern-central part and 405 species from an area $\left(20\right.$ sites, $\left.10 \mathrm{~m}^{2}\right)$ in the northernmost part along the Norwegian continental shelf. Shin and Ellingsen (2004) studied the spatial patterns of soft sediment benthic diversity in subtropical Hong Kong waters, and in this study, the sediment samples were collected and sieved on a $0.5-\mathrm{mm}$ sieve, and the retained fauna were fixed in $5 \%$ borax-buffered formalin and stained with $1 \%$ Rose Bengal for later sorting and identification. A total of 386 species from subtropical Hong Kong waters were reported according to Shin and Ellingsen (2004). Crame (2000) reported 1,176 bivalve species from the East China Sea, including Hong Kong, and 1,211 bivalve species from the IndonesiaPhilippines region. Bouchet et al. (2002) investigated species richness in the tropical waters on the west coast of New Caledonia of the Indo-Pacific. They surveyed an area covering approximately $295 \mathrm{~km}^{2}$, and 42 discrete stations were sampled by intertidal collecting, scuba diving, and dredging and found 2,738 species of marine mollusks. Compared to the studies in these coastal areas investigated before, Tolo Harbour displayed relatively lower species diversity because only 77 species were found.
Table 2 summarized the total number of species (species richness), total number of individuals (abundance), ShannonWeaver diversity $\left(H^{\prime}\right)$, and evenness $\left(J^{\prime}\right)$ at 13 sampling locations in Tolo Harbour. The Shannon-Weaver diversity and evenness ranged from 0.69 to 2 and from 0.37 to 1 , respectively. The number of species recorded varied through Tolo Harbour, with three sites (sites D, F, and L) displaying no species, while the species richness at sites $\mathrm{Y}$ and $\mathrm{Z}$ amounted to 43 and 40, respectively, and the total abundance at site $\mathrm{Y}$ was even as high as 15,207 individuals per square meter (Table 2). Site $\mathrm{Y}$ was the highest in total number of species and total number of individuals. Shannon-Weaver diversity and species richness showed the maximum values at site $\mathrm{Y}\left(H^{\prime}=2, S=43\right)$, followed by site $\mathrm{Z}\left(H^{\prime}=2, S=40\right)$, and site $\mathrm{P}\left(H^{\prime}=2, S=15\right)$. Of the three sites $(\mathrm{Y}, \mathrm{Z}$, and $\mathrm{P})$, site $\mathrm{P}$ displayed the highest evenness $\left(J^{\prime}=0.80\right)$, indicating that macrobenthic community at site $\mathrm{P}$ exhibited less variation in abundance. Except for sites D, F, and L, which were with azoic sediments void of macrobenthos, sites A and B located near Tai Po exhibited the lowest species diversity and abundance. There were two species, polychaete $P$. verrucosa pacifica and crustacean Lucifer typus, each with four individuals, which occurred at site A and only one species, crustacean L. typus, belonging to decapoda with eight individuals occurring at site $\mathrm{B}$.

Macrobenthic community found at sites $\mathrm{G}$ and $\mathrm{H}$ located near Sha Tin was more abundant and diverse compared to those at sites A and B. Changes of the macrobenthos from sites $\mathrm{G}$ to $\mathrm{H}$ were also observed in Tolo Harbour. The abundance of opportunistic species such as polychaete Phyllodoce lineata (Mistri 2002; Tomassetti and Porrello 2005; Ingole et al. 2009) was higher at site H compared to site G; conversely, the abundance of metal-sensitive species such as mollusks and crustaceans present at site $G$ were lower or totally absent at site $\mathrm{H}$. Though the total abundance at site $\mathrm{H}$ was higher $(N=1,707)$ than that of site $\mathrm{G}(N=200)$, the most dominant species $(P$. lineata, $N=1,387)$ constituted

Table 1 Ten most abundant species in Tolo Harbour

\begin{tabular}{|c|c|c|c|c|}
\hline Faunal group & Species name & $N$ & Dominance $(\%)$ & Cumulative dominance $(\%)$ \\
\hline Polychaeta (P) & Pherusa sp. & 8,613 & 38.38 & 38.38 \\
\hline Polychaeta (P) & Nephtys polybranchia & 2,347 & 10.46 & 48.84 \\
\hline Polychaeta (P) & Phyllodoce lineata & 2,312 & 10.3 & 59.14 \\
\hline Polychaeta (P) & Pilargis verrucosa pacifica & 1,260 & 5.62 & 64.76 \\
\hline Bivalve (M) & Vignadula atrata & 800 & 3.57 & 68.32 \\
\hline Crustacean (C) & Calliopius sp. & 753 & 3.36 & 71.68 \\
\hline Polychaeta (P) & Eunice indica & 653 & 2.91 & 74.59 \\
\hline Bivalve (M) & Musculus japoncia & 627 & 2.79 & 77.38 \\
\hline Echinodermata $(\mathrm{E})$ & Ophiactidae sp. & 580 & 2.58 & 79.96 \\
\hline Polychaeta (P) & Epidiopatra hupferianna & 309 & 1.38 & 81.34 \\
\hline
\end{tabular}

$N$ number of individuals per square meter, $P$ polychaete, $M$ mollusks, $C$ crustaceans, $E$ echinoderms 
Table 2 Species richness, total number of individuals, ShannonWeaver index, evenness at 13 sampling locations in Tolo Harbour

\begin{tabular}{lcrll}
\hline Sites & $\begin{array}{l}S \text { (species } \\
\text { richness) }\end{array}$ & $\begin{array}{l}N \text { (total abundance } \\
\text { (individuals per } \\
\text { square meter) }\end{array}$ & $\begin{array}{l}H^{\prime} \text { (Shannon- } \\
\text { Weaver index) }\end{array}$ & $J^{\prime}$ (evenness) \\
\hline A & 2 & 8 & 0.69 & 1 \\
B & 1 & 8 & - & - \\
D & 0 & 0 & - & - \\
F & 0 & 0 & - & - \\
G & 7 & 200 & 1.60 & 0.82 \\
H & 10 & 1,707 & 0.85 & 0.37 \\
L & 0 & 0 & - & - \\
N & 3 & 52 & 1.01 & 0.92 \\
P & 15 & 192 & 2 & 0.80 \\
V & 4 & 28 & 1.15 & 0.83 \\
X & 5 & 160 & 0.70 & 0.44 \\
Y & 43 & 15,207 & 2 & 0.51 \\
Z & 40 & 4,887 & 2 & 0.59 \\
\hline
\end{tabular}

$H^{\prime}$ is calculated using natural logarithms

Date presented here are based on the results of five pooled samples

$81.25 \%$ of the total number of species at site $\mathrm{H}$, which led to lower Shannon-Weaver index $\left(H^{\prime}=0.85\right)$ and evenness $\left(J^{\prime}=\right.$ $0.37)$ compared to those at site $\mathrm{G}\left(H^{\prime}=1.60, J^{\prime}=0.82\right)$.

There was a significant decrease in the total number of species, species abundance, and Shannon-Weaver diversity from Plover Cove (sites $\mathrm{Y}$ and $\mathrm{Z}$ ) to inner Tolo Harbour (sites $\mathrm{D}, \mathrm{F}, \mathrm{A}, \mathrm{B}, \mathrm{H}$, and $\mathrm{G})$. The three sites $(\mathrm{L}, \mathrm{N}$, and $\mathrm{P})$ investigated in Tolo Channel showed increasing species richness $(\mathrm{L}, S=0$; $\mathrm{N}, S=3 ; \mathrm{P}, S=15)$, total abundance (L, $N=0 ; \mathrm{N}, N=52 ; \mathrm{P}, N=$ $192)$, and Shannon-Weaver diversity $\left(\mathrm{L}, H^{\prime}=0 ; \mathrm{N}, H^{\prime}=1.01\right.$; $\left.\mathrm{P}, H^{\prime}=2\right)$ as the distance to inner harbor increased. It should be noted that the distinctive feature of site $\mathrm{P}$ was the presence of two species of high trophic (demersal fish) level which rely on the macrobenthos for food.

Group average linkage cluster analysis for macrobenthic community was performed using PRIMER software package (Clarke and Warwick, 1994). Before cluster analysis, a triangular similarity matrix between every pair of locations was constructed using fourth-root transformed species abundance data and the Bray-Curtis similarity measures. The macrobenthic community in Tolo Harbour formed three distinctive groups (Fig. 2) based on the above calculation results. Group I included only two stations (H and G) characterized by low diversity. Polychaetes dominated the community of the two stations. Group II covering five stations was mainly located in the inner Tolo Harbour. Species richness occurring at the five stations was very impoverished, and the maximum of the species richness of group II was five and occurred at site X (Table 2). Group III represented the macrobenthic community of the three stations (sites Y, Z, and P). Two stations located in Plover
Cove (sites $\mathrm{Y}$ and $\mathrm{Z}$ ) and one station was in Tolo Channel with the longest distance to inner Tolo Harbour of the 13 stations. The macrobenthic community of group III was characterized by high diversity with the highest number of species and abundance among the three groups.

\section{Effect of Heavy Metals on Macrobenthic Community}

Environmental disturbances may cause structural changes in macrobenthic community and influence species diversity due to different species' stress tolerances (Gray and Pearson 1982; Rygg 1985a). Tolerant or opportunistic species tend to dominate stressed assemblages, and less tolerant species tend to become increasingly rare or even extinct. Somerfield et al. (1994) demonstrated that heavy metal concentrations in sediments correlated most strongly with the composition of biological community and were the most likely causal agents. Railken (2004) divided marine aquatic organisms into the following groups according to their toxic resistance to heavy metals: more sensitive (crustaceans), less sensitive (mollusks), and, finally, resistant (polychaetes). Heavy metal concentrations and distributions in the 13 stations were examined to investigate the possible effect of heavy metals on macrobenthic community in the harbor. Table 3 lists the measured sediment concentrations of four heavy metals $(\mathrm{Cu}, \mathrm{Zn}, \mathrm{Cd}$, and $\mathrm{Pb})$ from the 13 sampling sites. In general, the levels of $\mathrm{Cu}, \mathrm{Zn}, \mathrm{Cd}$, and $\mathrm{Pb}$ in inner harbor (sites A, B, D, H, G, F, X, and V) were higher than those in Tolo Channel (sites L, N, and P) and Plover Cove (sites $\mathrm{Y}$ and Z). The sites (sites A, B, and D) located near Tai Po were more polluted with heavy metals than those near Sha Tin (sites F, G, and H). The 13 sites were clustered to three groups based on heavy metal concentrations (Fig. 3).

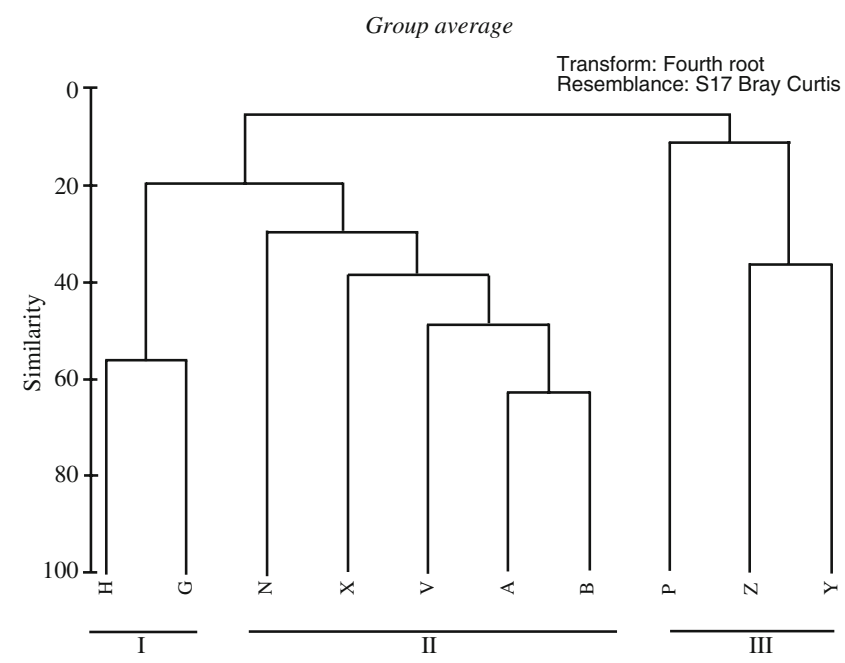

Fig. 2 Group average cluster analysis of the similarity of the macrofaunal community. Sites D, F, and L were void of macrofauna and not included in the analysis 
Table 3 Heavy metal concentrations $\left(\mathrm{mg} \mathrm{kg}^{-1}\right)$ in sediments from Tolo Harbour

\begin{tabular}{lllll}
\hline Sites & $\mathrm{Cu}$ & $\mathrm{Zn}$ & $\mathrm{Cd}$ & $\mathrm{Pb}$ \\
\hline $\mathrm{A}$ & 55.39 & 436.2 & 1.52 & 140.5 \\
$\mathrm{~B}$ & 51.72 & 645 & 1.28 & 139 \\
$\mathrm{D}$ & 52.46 & 252.4 & 0.99 & 111.3 \\
$\mathrm{~F}$ & 32.35 & 144.3 & 0.62 & 72.53 \\
$\mathrm{G}$ & 66.33 & 250.8 & 1.31 & 90.2 \\
$\mathrm{H}$ & 18.67 & 124.6 & 0.8 & 47.67 \\
$\mathrm{~L}$ & 36.56 & 174.2 & 0.78 & 70.65 \\
$\mathrm{~N}$ & 36.89 & 162.6 & 0.57 & 59.72 \\
$\mathrm{P}$ & 28.75 & 123.2 & 0.29 & 46.02 \\
$\mathrm{~V}$ & 50.41 & 208.5 & 1.05 & 94.96 \\
$\mathrm{X}$ & 72.38 & 188.3 & 1.04 & 83.77 \\
$\mathrm{Y}$ & 8.19 & 53.19 & 0.23 & 22.82 \\
$\mathrm{Z}$ & 10.39 & 51.52 & 0.08 & 34.45 \\
\hline
\end{tabular}

Group I included sites H, G, D, F, and L. Sites N, X, V, A, and $\mathrm{B}$ formed group II, and it was interesting to observe that group II, based on heavy metal concentrations, included the same sites as group II based on the similarity of macrofaunal community (Fig. 2). Group III based on heavy metal concentrations and the similarity of macrofaunal community also included the same sites. The consistent results of the cluster analyses based on heavy metal concentrations and macrofaunal community suggests a potential cause-effect relationship.

The concentrations of the four heavy metals at sites $\mathrm{Y}$ and $\mathrm{Z}$ generally displayed the lowest levels associated with the richest species and individuals. An overall increase in the concentrations of heavy metals associated with the decrease in species richness $(S)$ and diversity $\left(H^{\prime}\right)$ was observed through Tolo Harbour. For example, sites A and B with higher levels of $\mathrm{Cu}, \mathrm{Pb}$, and $\mathrm{Zn}$ than those in sites $\mathrm{H}$ and $\mathrm{G}$ exhibited lower species diversity than that of sites $\mathrm{H}$ and G. Figure 4 displays the relation between heavy metals $(\mathrm{Cu}, \mathrm{Pb}, \mathrm{Zn}$, and $\mathrm{Cd})$ and species diversity at the 13 sites. The overall trend that can be observed is that the total abundance and species richness increase as the concentrations of heavy metals decrease. From Fig. 4, it can be seen that the relation between them is not linear, indicating that the relation is complicated and heavy metals are not the only factor controlling total abundance and species richness. Pearson correlation coefficient between heavy metals concentrations, species richness, total abundance, ShannonWeaver index, and evenness were calculated and listed in Table 4. It was found that species richness, total abundance, and Shannon-Weaver index were all negatively correlated with the four heavy metal concentrations (Table 4), and the negative correlation between species richness of macrobenthos and the four heavy metal concentrations were significant. The total abundance and Shannon-Weaver index were also significantly negatively correlated with three of the heavy metal concentrations. The evenness did not correlate with these heavy metal concentrations, indicating that heavy metal concentrations did not influence the evenness of the macrobenthic community. These results provided strong evidence of pollution-induced degradation of macrobenthos in Tolo Harbour. Therefore, the significant increase in the number of both individuals and species in sites $\mathrm{Y}$ and $\mathrm{Z}$ suggested better environmental quality or a shift to low pollution levels (Warwick 2001) in these areas.

The relationship between macrobenthic community and heavy metals was also studied by previous researchers (Rygg 1985b; Roper and Hickey 1994; Hall et al. 1996; Morrisey et al. 1996; Mucha et al. 2003; Burlinson and Lawrence 2007). These previous studies documented negative correlation between macrobenthic diversity and heavy metals, which are consistent with our findings. In a study of the ecological effects of contamination by heavy metals in Norwegian fjords, Rygg (1985b) found that of the 50 most commonly occurring species, 29 were absent or only rarely present at sites where the concentration of copper exceeded $200 \mu \mathrm{g} \mathrm{g}^{-1}$. Morrisey et al. (1996) conducted field experiments and found that increased concentrations of $\mathrm{Cu}$ in the sediments caused significant changes to soft sediment assemblage. Roper and Hickey (1994) found that bivalves moved away from sandy sediments experimentally treated with copper in the laboratory. They found that the maximal response of bivalves to copper occurred at concentration of $25 \mu \mathrm{g} \mathrm{g}^{-1}$ in the sediment, which was less than the $\mathrm{Cu}$ concentration at most sites in the present study; a detectable response occurred at $5 \mu \mathrm{g} \mathrm{g}^{-1}$. Burlinson and Lawrence (2007) demonstrated that Mylor Creek worms were sensitive when exposed to $4 \mathrm{mg} \mathrm{L}^{-1}$ of copper in an acute assay, and the tolerance of Rostronguet Creek worms increased moving upstream from the mouth of the Creek.

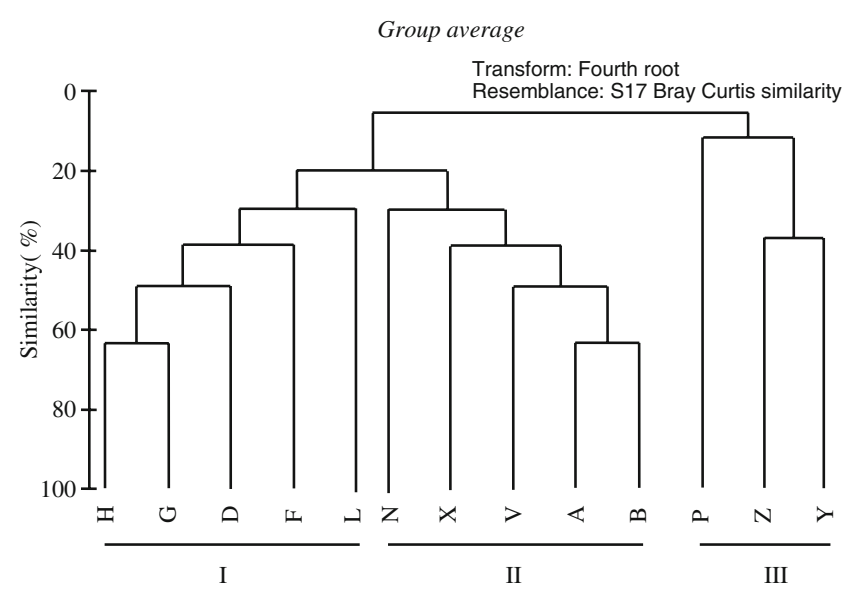

Fig. 3 Cluster analysis of the similarity of the 13 sites based on heavy metal concentrations 
Fig. 4 Heavy metal concentrations compared with abundance and species diversity in Tolo Harbour

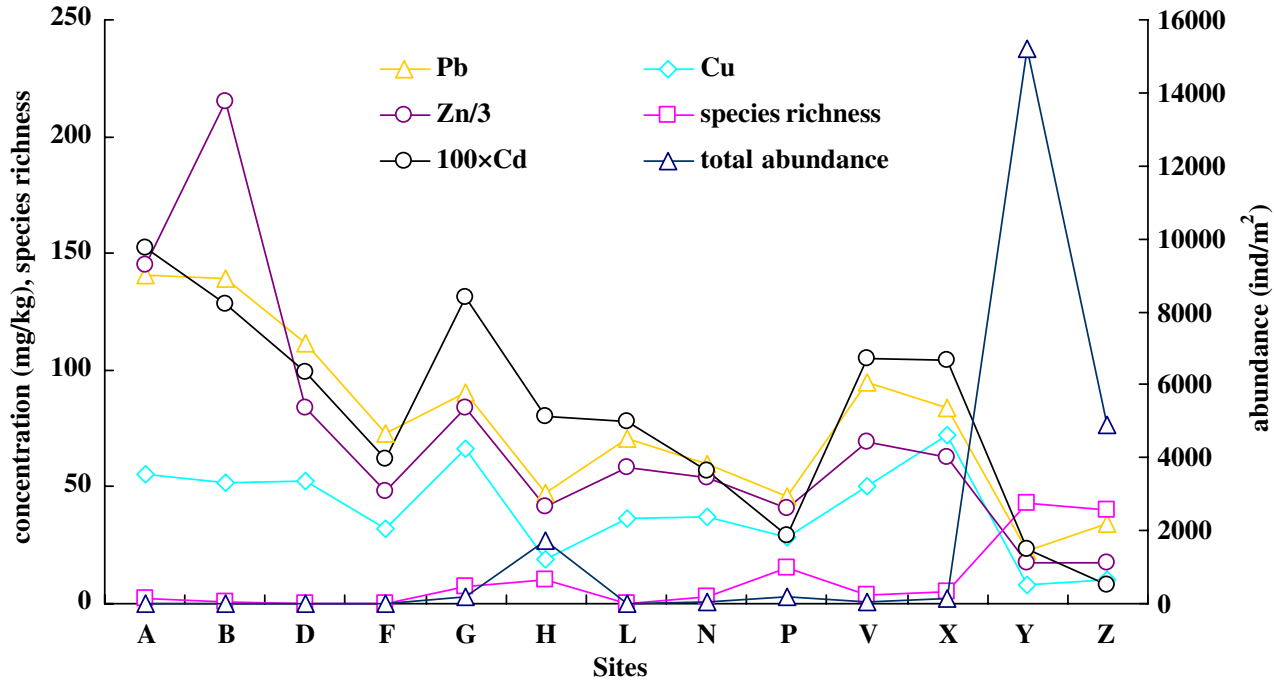

According to previous studies (Rand and Petrocelli 1985; Morrisey et al. 1996; Warwick 2001), many crustacean species are sensitive to heavy metals. In Tolo Harbour, only eight species within 1,296 individuals of crustaceans were found, and $95 \%$ of the individuals were found at sites $\mathrm{Y}$ and $\mathrm{Z}$. Except for L. typus, almost no crustaceans were present at the other 11 sampling sites. The rare presence of crustaceans in the 11 sites thus suggested severe pollution. This was consistent with high levels of heavy metals in these sites compared to the sediment quality guideline set by the Hong Kong government. This indicates that heavy metal concentrations in sediments in the 11 stations were high enough to cause toxicity and might be responsible for the almost absence of crustaceans.

Comparing macrobenthic community of the 13 stations in Tolo Harbour suggested that polychaetes were generally less sensitive than any other major macrobenthic taxon to heavy metal pollution. Many species of polychaetes have a high level of tolerance to adverse effects such as heavy metal pollution. It was found that even the stations with extremely high levels of heavy metals, such as site A in inner harbor, one opportunistic species of Polychaete $P$. verrucosa pacifica can still survive. Another effect, potentially attributed to the high concentrations of heavy metals, on the macrobenthic fauna observed in Tolo Harbour was the absence of sensitive species such as crustaceans and dominance of some small opportunistic species such as Pherusa sp. at sites G, H, X, and V. In general, the macrobenthic distribution pattern in Tolo Harbour was in good agreement with the classic model proposed by Pearson and Rosenberg (1978). According to this model, the macrobenthic community undergoes several successive stages from normal community structure with diverse fauna, transitional community composition with increase in opportunistic species, peak in arrival of opportunistic species, and eventually to azoic sediment void of macrobenthos.

\section{Conclusion}

This investigation of macrobenthic community and its correlation to heavy metal concentrations in sediment from

Table 4 Pearson correlation coefficient between metal concentrations and biological parameters

\begin{tabular}{|c|c|c|c|c|c|c|c|c|}
\hline & $\mathrm{Cu}$ & $\mathrm{Zn}$ & $\mathrm{Cd}$ & $\mathrm{Pb}$ & $\mathrm{S}$ & $\mathrm{N}$ & $H^{\prime}$ & $J^{\prime}$ \\
\hline $\mathrm{Cu}$ & 1 & 0 & & & & & & \\
\hline $\mathrm{Zn}$ & 0.567 & 1 & & & & & & \\
\hline $\mathrm{Cd}$ & $0.834^{\mathrm{a}}$ & $0.768^{\mathrm{a}}$ & 1 & & & & & \\
\hline $\mathrm{Pb}$ & $0.763^{\mathrm{b}}$ & $0.921^{\mathrm{a}}$ & $0.910^{\mathrm{a}}$ & 1 & & & & \\
\hline S (species richness) & $-0.780^{\mathrm{a}}$ & -0.625 & $-0.795^{\mathrm{a}}$ & $-0.746^{\mathrm{a}}$ & 1 & & & \\
\hline $\mathrm{N}$ (total abundance) & $-0.662^{b}$ & -0.455 & -0.575 & -0.595 & $0.860^{\mathrm{a}}$ & 1 & & \\
\hline H' (Shannon-Weaver index) & -0.557 & $-0.787^{\mathrm{a}}$ & $-0.733^{\mathrm{b}}$ & $-0.768^{\mathrm{a}}$ & $0.754^{\mathrm{a}}$ & 0.529 & 1 & \\
\hline$J^{\prime}$ (evenness) & 0.111 & -0.314 & 0.007 & -0.046 & -0.102 & -0.178 & 0.411 & 1 \\
\hline
\end{tabular}

${ }^{\text {a }}$ Correlation is significant at the 0.01 level (two-tailed)

${ }^{\mathrm{b}}$ Correlation is significant at the 0.05 level (two-tailed) 
Tolo Harbour showed that some areas displayed both high species richness and abundance, while other areas were quite impoverished or even void of macrobenthos in Tolo Harbour. Compared with other coastal areas from the literature, macrobenthic community in Tolo Harbour had a low diversity, with only 77 species found through Tolo Harbour. Most of these species occurred in sites $\mathrm{Y}$ and $\mathrm{Z}$ and no species found in sites D, F, and L. Of the 77 species found in Tolo Harbour, no single species was found at all sites. The most common species was polychaete $P$. verrucosa pacifica found at six sites.

The present findings support the proposed relationship between metal concentrations and macrobenthic diversity in Tolo Harbour. An overall increase in the concentrations of heavy metals associated with the decrease in species richness and diversity was observed through Tolo Harbour. In sites with high metal levels, only some opportunistic species such as polychaete $P$. lineata occurred and sensitive species were absent or rare.

Acknowledgments The authors wish to thank Robin Liu and Phil $\mathrm{Xu}$ for assistance in field sampling. This study was supported by a grant from the Research Grants Council of Hong Kong (HKU 7028/ 06P) and open fund from Nanjing Hydraulic Research Institute.

\section{References}

Bouchet, P., P. Lozouet, P. Maestrati, and V. Heros. 2002. Assessing the magnitude of species richness in tropical marine environments: Exceptionally high numbers of molluscs at a New Caledonia site. Biological Journal of the Linnean Society 75: 421-436.

Burlinson, F.C., and A.J. Lawrence. 2007. A comparison of acute and chronic toxicity tests used to examine the temporal stability of a gradient in copper tolerance of Hediste diversicolor from the Fal estuary, Cornwall, UK. Marine Pollution Bulletin 54: 66-71.

Chapman, P.M., and F. Wang. 2001. Assessing sediment contamination in estuaries. Environmental Toxicology and Chemistry 20: 3-22.

Chen, K.P., and J.J Jiao. 2010. Spatio-temporal trends of heavy metals and source apportionment in Tolo Harbour, Hong Kong. Environmental Earth Sciences. doi:10.1007/s12665-009-0279-y.

Clarke, K.R., and R.M. Warwick. 1994. Change in marine communities: An approach to statistical analysis and interpretation, 144. Plymouth, UK: Natural Environment Research Council.

Crame, J.A. 2000. Evolution of taxonomic diversity gradients in the marine realm: Evidence from the composition of recent bivalve faunas. Paleobiology 26: 188-241.

Dauvin, J.C. 2008. Effects of heavy metal contamination on the macrobenthic fauna in estuaries: The case of the Seine estuary. Marine Pollution Bulletin 57(1-5): 22-40.

Ellingsen, K.E., and J.S. Gray. 2002. Spatial patterns of benthic diversity: Is there a latitudinal gradient along the Norwegian continental shelf? Journal of Animal Ecology 71: 373-389.

Estacio, F.J., E.M. García-Adiego, F.D.A. García-Gómez, J.L. Daza, F. Hortasand, and J.L. Gómez-Ariza. 1997. Ecological analysis in a polluted area of Algeciras Bay (Southern Spain): External versus internal outfalls and environmental implications. Marine Pollution Bulletin 34: 780-793.

Grassle, J.F., and J.P. Grassle. 1974. Opportunistic life histories and genetic systems in marine benthic polychaetes. Journal of Marine Research 32(2): 253-284.

Gray, J.S. 1994. Is deep-sea species diversity really so high? Species diversity of the Norwegian continental shelf. Marine Ecology Progress Series 112: 205-209.

Gray, J.S., and T.H. Pearson. 1982. Objective selection of sensitive species indicative of pollution-induced changes in benthic communities. I. Comparative methodology. Marine Ecology Progress Series 9: 111-119.

Guerra-García, J.M., and J.C. García-Góme. 2004. Polychaete assemblages and sediment pollution in a harbour with two opposing entrances. Helgoland Marine Research 58: 183-191.

Hall, J.A., C.L.J. Frid, and R.K. Proudfoot. 1996. Effects of metal contamination on macrobenthos of two North Sea estuaries. ICES Journal of Marine Science 53: 1014-1023.

Harriague, A.C., C. Misic, M. Petrillo, and G. Albertelli. 2007. Stressors affecting the macrobenthic community in Rapallo Harbour (Ligurian Sea, Italy). Scientia Marina 71(4): 705-714.

Ingole, B., S. Sivadas, M. Nanajkar, S. Sautya, and A. Nag. 2009. A comparative study of macrobenthic community from harbours along the central west coast of India. Environmental Monitoring and Assessment 154: 135-146.

Jiao, J.J., X.S. Wang, and S. Nandy. 2005. Confined groundwater zone and slope instability in weathered igneous rocks in Hong Kong. Engineering Geology 80: 71-92.

Jiao, J.J., X.S. Wang, and S. Nandy. 2006. Preliminary assessment of the impacts of deep foundations and land reclamation on groundwater flow in a coastal area in Hong Kong, China. Hydrogeology Journal 14: 100-114.

Mistri, M. 2002. Persistence of benthic communities: A case study from the Valli di Comacchio, a Northern Adriatic lagoonal ecosystem (Italy). Ices Journal of Marine Science 59(2): 314 322.

Morrisey, D.J., A.J. Underwood, and L. Howitt. 1996. Effects of copper on the faunas of marine soft-sediments: A field experimental study. Marine Biology 125: 199-213.

Mucha, A.P., M.T.S.D. Vasconcelos, and A.A. Bordalo. 2003. Macrobenthic community in the Douro estuary: Relations with trace metals and natural sediment characteristics. Environmental Pollution 121: 169-180.

Pearson, T.H., and R. Rosenberg. 1978. Macrobenthic succession in relation to organic enrichment and pollution of the marine environment. Oceanography and Marine Biology Annual Review 16: 229-311.

Railken, A.I. 2004. Marine biofouling: Colonization processes and defenses. Boca Raton: CRC.

Rand, G.M., and S.R. Petrocelli. 1985. Fundamentals of aquatic toxicology. Washington: Hemisphere.

Roper, D.S., and C.W. Hickey. 1994. Behavioural responses of the marine bivalve Macomona liliana exposed to copper- and chlordane-dosed sediments. Marine Biology 118: 673-680.

Rygg, B. 1985a. Distribution of species along pollution-induced diversity gradient in benthic communities in Norwegian Fjords. Marine Pollution Bulletin 16: 469-474.

Rygg, B. 1985b. Effect of sediment copper on benthic fauna. Marine Ecology Progress Series 25: 83-89.

Shannon, C.E., and W. Weaver. 1963. The mathematical theory of communications. Urbana: University of Illinois Press.

Shin, P.K.S., and K.E. Ellingsen. 2004. Spatial patterns of softsediment benthic diversity in subtropical Hong Kong waters. Marine Ecology Progress Series 276: 25-35. 
Somerfield, P.J., J.M. Gee, and R.M. Warwick. 1994. Benthic community structure in relation to an instantaneous discharge of waste water from a tin mine. Marine Pollution Bulletin 28: 363369.

Tomassetti, P., and S. Porrello. 2005. Polychaetes as indicators of marine fish farm organic enrichment. Aquaculture International 13: $109-128$

Tse, K.C., and J.J. Jiao. 2008. Estimation of submarine groundwater discharge in Plover Cove, Tolo Harbour, Hong Kong by ${ }^{222} \mathrm{Rn}$. Marine Chemistry 111: 160-70.
Warwick, R.M. 2001. Evidence for the effects of metal contamination on the intertidal macrobenthic assemblages of the Fal Estuary. Marine Pollution Bulletin 42(2): 145-148.

Xu, F.L., K.C. Lam, R.W. Dawson, S. Tao, and Y.D. Chen. 2004. Longterm temporal-spatial dynamics of marine coastal water quality in the Tolo Habor, Hong Kong, China. Journal of Environmental Sciences 16(1): 161-166.

Yim, W.W.S. 1984. Geochemical mapping of bottom sediments as an aid to marine waste disposal in Hong Kong. Resources Conservation and Recycling 7(2-4): 309-320. 